\title{
Carboidrases exógenas e a saúde intestinal de aves
}

\author{
Exogenous carbohydrases and gut health in birds \\ Las carbohidrasas exógenas y la salud intestinal de los animales no rumiantes
}

Gabriel Miranda Macambira ORCID: https://orcid.org/0000-0002-0277-5286 Universidade Federal Rural de Pernambuco, Brasil E-mail: gabriel.miranda.zootecnia@gmail.com

Carlos Bôa Viagem Rabello ORCID: https://orcid.org/0000-0002-5912-162X Universidade Federal Rural de Pernambuco, Brasil E-mail: carlos.boaviagem@gmail.com

Cláudia da Costa Lopes

ORCID: https://orcid.org/0000-0002-2888-9839 Universidade Federal do Rio Grande do Norte, Brasil E-mail: cclway@yahoo.com.br

Marcos José Batista dos Santos

ORCID: https://orcid.org/0000-0002-6023-3426

Universidade Federal Rural de Pernambuco, Brasil E-mail: marcoszootecnista@gmail.com

Apolônio Gomes Ribeiro

ORCID: https://orcid.org/0000-0001-6730-0209

Universidade Federal Rural de Pernambuco, Brasil E-mail: apoloniogomes962@gmail.com

Hélia Sharlane de Holanda Oliveira

ORCID: https://orcid.org/0000-0002-4314-4827

Universidade Federal Rural de Pernambuco, Brasil E-mail: Sharlaneho@yahoo.com

Dayane Albuquerque da Silva

ORCID: https://orcid.org/0000-0001-6243-3969

Universidade Federal Rural de Pernambuco, Brasil

E-mail: dayane.albuquerque.ds@gmail.com

Ana Carolina Ferreira dos Santos

ORCID: https://orcid.org/0000-0003-0361-5222

Universidade Federal Rural de Pernambuco, Brasil

E-mail: carolufrpe@ hotmail.com

Maria Aline Alves Mota

ORCID: https://orcid.org/0000-0001-7171-7648

Universidade Federal Rural de Pernambuco, Brasil

E-mail: mariaaline168@gmail.com

Mirelio Ferreira da Silva

ORCID: https://orcid.org/0000-0003-2692-663X Universidade Federal do Ceará, Brasil

E-mail: mireliosilva@gmail.com

Zaqueu Ferreira Rodrigues

ORCID: https://orcid.org/0000-0003-2813-9998

Universidade Federal Rural de Pernambuco, Brasil

E-mail: zfracademico@gmail.com

Marcos Rafael de Sousa Rodrigues

ORCID: https://orcid.org/0000-0002-8572-8337 Universidade Federal dos Vales do Jequitinhonha e Mucuri, Brasil

E-mail: marcoscrate10@gmail.com

Maria Lorrane Saldanha Ferreira ORCID: https://orcid.org/0000-0002-9585-6164 Universidade Federal Rural de Pernambuco, Brasil

E-mail: saldanha.mlm@gmail.com

Jéssica Berly Moreira Marinho

ORCID: https://orcid.org/0000-0002-3826-7670

Universidade Federal Rural de Pernambuco, Brasil

E-mail: jessicaberlymm@gmail.com

Gabriela Duarte Silva

ORCID: https://orcid.org/0000-0001-9688-8881

Universidade Federal Rural de Pernambuco, Brasil

E-mail: gabrieladuarte1059127@gmail.com 


\title{
Katariny Lima de Abreu \\ ORCID: https://orcid.org/0000-0002-8506-1827 \\ Universidade Federal Rural de Pernambuco, Brasil E-mail: kahabreeu@gmail.com \\ Jéssica Maria dos Santos Silva \\ ORCID: https://orcid.org/0000-0001-5524-9987 \\ Universidade Federal dos Vales do Jequitinhonha e Mucuri, Brasil E-mail: jessicasilva12213@gmail.com
}

\begin{abstract}
Resumo
A maior parte dos ingredientes destinados a alimentação de animais não ruminantes se constituem de origem vegetal e podem conter, em sua composição, níveis variáveis de polissacarídeos não amiláceos (PNAs). Estes são conhecidos por comprometerem, a depender dos níveis de inclusão do ingrediente, concentrações e tipos nos alimentos, o desempenho e a saúde intestinal de suínos e aves. As carboidrases são enzimas que degradam carboidratos e tem sido utilizada como alternativas para melhorias no aproveitamento de fontes alimentares que contenham grandes quantidades de PNAs, com resultados positivos sobre aproveitamento energético da dieta e diminuindo os efeitos negativos desses compostos. Celulases, xilanases, betaglucases, amilases, galactosidades, dentre outras tem sido suplementadas nas rações desses animais e têm mostrado serem afetivas em melhorar as características morfométricas, estado imunológico e microbiano do intestino, com impactos positivos sobre a saúde intestinal e desempenho. Logo, estre trabalho teve por objetivo revisar os efeitos da utilização e enzimas carboidrases na dieta de aves e seus efeitos sobre a saúde intestinal.
\end{abstract}

Palavras-chave: Aditivos; Enzimas; Ingredientes; Saúde intestinal.

\begin{abstract}
Most feed ingredients for non-ruminant animals are of plant origin and may contain varying levels of non-starch polysaccharides (NAPs) in their composition. These are known to compromise, depending on ingredient inclusion levels, concentrations, and types in the feed, the performance and gut health of pigs and poultry. Carbohydrases are enzymes that degrade carbohydrates and have been used as alternatives to improve the utilization of feed sources that contain large amounts of PNAs, with positive results on energy utilization of the diet and reducing the negative effects of these compounds. Cellulases, xylanases, betaglucases, amylases, galactosities, among others have been supplemented in the feed of these animals and have shown to be effective in improving the morphometric characteristics, immune and microbial status of the intestine, with positive impacts on intestinal health and performance. Therefore, this study aimed to review the effects of the use of carbohydrase enzymes in poultry diets and their effects on gut health.
\end{abstract}

Keywords: Additives; Enzymes; Ingredients; Gut health.

\section{Resumen}

La mayoría de los ingredientes destinados a la alimentación de animales no rumiantes son de origen vegetal y pueden contener, en su composición, niveles variables de polisacáridos no amiláceos (PNA). Se sabe que, en función de los niveles de inclusión de ingredientes, las concentraciones y los tipos de piensos, comprometen el rendimiento y la salud intestinal de los cerdos y las aves de corral. Las carbohidrasas son enzimas que degradan los hidratos de carbono y se han utilizado como alternativas para mejorar el aprovechamiento de las fuentes alimentarias que contienen grandes cantidades de ANP, con resultados positivos en la utilización energética de la dieta y la reducción de los efectos negativos de estos compuestos. Celulasas, xilanasas, betaglucasas, amilasas, galactosas, entre otras, han sido suplementadas en la alimentación de estos animales y han demostrado ser afectivas en la mejora de las características morfométricas, el estado inmunológico y microbiano del intestino, con impactos positivos en la salud intestinal y el rendimiento. Por lo tanto, este estudio tenía como objetivo revisar los efectos del uso de enzimas carbohidrasas en las dietas de aves de corral y sus efectos en la salud intestinal.

Palabras clave: Aditivos; Enzimas; Ingredientes; Salud intestinal.

\section{Introdução}

Com o crescente aumento da população mundial, tem-se incrementado também a demanda por proteína animal segura e de qualidade. A proibição do uso de antibióticos na produção animal, em vários países do mundo, tornou-se um desafio para os nutricionistas da atualidade, levando-os a buscarem alimentos, em sua maioria vegetais, que apresentem compostos com características promotoras de crescimento (Anwar et al., 2017; Cheng et al., 2019).

A nutrição, juntamente com outras áreas, com destaque para ambiência, melhoramento genético e sanidade, se destaca com o aparecimento de inúmeras alternativas, tais como a utilização de enzimas exógenas, no incremento do aproveitamento dos ingredientes das rações, principalmente quando se utilizam alimentos alternativos que possuem altos teores de fibra e 
compostos antinutricionais (Vargas et al, 2017). Ainda segundo o mesmo autor, alimentos ricos em fitatos e polissacarídeos não amiláceos (PNAs) não são aproveitados eficientemente pelos animais não ruminantes, principalmente devido à ausência na síntese de enzimas específicas, por parte desses animais, para a degradação desses tipos de compostos.

As carboidrases são enzimas que degradam carboidratos através da hidrólise das ligações glicosídicas entre as suas unidades monoméricas e tem sido utilizada, na nutrição de não ruminantes, como alternativa para melhorias no aproveitamento de alimentos que contenham grandes quantidades de PNAs, melhorando o aproveitamento energético da dieta e diminuindo os efeitos negativos desses polímeros no trato gastrointestinal desses animais (Fortes et al., 2012; Ferreira et al., 2015).

Diante do exposto, este trabalho tem por objetivo revisar os efeitos da utilização e enzimas carboidrases na dieta de aves e seus efeitos sobre a saúde intestinal desses animais.

\section{Metodologia}

O presente estudo trata-se de uma revisão narrativa acerca do uso de carboidrases exógenas e seus efeitos sobre a saúde intestinal de aves. A revisão abrangeu, em sua maioria, artigos científicos, mas foram também utilizadas teses e dissertações presentes na base de dados do Scielo (Scientific Eletronic Library Online), Science Direct e Google Acadêmico. Descartou-se trabalhos sem resumo e que não abordavam a temática do estudo, assim como aqueles que apresentavam metodologias mal aplicadas ou suspeitas.

\section{Revisão Bibliográfica}

\subsection{Polissacarídeos não amináceos (PNAs)}

A maior parte da composição das rações destinadas a alimentação de não ruminantes é composta de ingredientes de origem vegetal, sendo o milho e o farelo de soja os principais ingredientes, em termos de energia e proteína, utilizados. Os carboidratos, nas plantas, podem ser divididos em amido e PNAs. O amido é o carboidrato de reserva energética primordial nestes organismos. Os PNAs têm função principalmente estrutural e de proteção, formando a cobertura externa das principais estruturas das plantas, tal como a parede celular (Bederska-Łojewska et al., 2017).

Segundo Smits e Annison (1996) e Fortes et al., (2012), a constituição básica dos PNAs é celulose, hemicelulose, $\beta$ glucanos, xilanos, arabinoxilanos, dentre outros. Esses polímeros, de acordo estes pesquisadores, apresentam ligações glicosídicas ( $\beta$ 1-4 e $\beta$ 1-6) diferentes daquelas encontradas no amido ( $\alpha$ 1-4 e $\alpha$ 1-6) e são resistentes as enzimas animais, mas podem ser clivadas por enzimas sintetizadas por micro-organismos. Os PNAs são classificados em solúveis e insolúveis de acordo com as suas propriedades de retenção de água.

Tavernari et al. (2008) nos diz que dentre os PNAs solúveis encontram-se a hemicelulose (xiloglucanos, arabinoxilanos, $\beta$-glucanos, dentre outros), gomas e pectinas. Os PNAs solúveis têm grande capacidade de absorver água, o que lava a aumento na viscosidade do quimo, diminuí o trânsito intestinal, aumenta o volume da digesta e compromete a dissociação de enzimas e substratos, acarretando em comprometimentos na digestibilidade e aproveitamento dos alimentos e aumentos no conteúdo de água em fezes e excretas, além de incrementarem a hidrólise de sais biliares com consequente diminuição na digestão das gorduras (Fireman e Fireman, 1998; Adeola e Bedford, 2004; Vahjen et al., 2007; Tahir et al., 2008; Tavernari et al., 2008; Nitriyová et al., 2009; Jha e Berrocoso, 2015). Além disso, segundo Wagner e Thomas (1978), a diminuição do trânsito no intestino, associado a uma baixa tensão de oxigênio pode tornar este ambiente estável, onde uma microbiota fermentativa se estabelece e leva, de acordo com Choct et al. (1996), a desequilíbrios no ecossistema intestinal e prejuízos ao desempenho e saúde do intestino dos animais. 
Dentre os PNAs insolúveis, a celulose e a lignina são os constituintes mais importantes (Tavernari et al., 2008), estando presente também hemiceluloses insolúveis, cutina e outros compostos em menores proporções (Van Soest et al., 1991). Esse tipo de fibra, segundo Warpechowisk (1996), tem a capacidade de prejudicar a digestibilidade dos ingredientes devido ao incremento da motilidade e consequente trânsito intestinal, diminuindo o tempo de permanência da digesta em contato com as enzimas digestivas endógenas, além de terem um enfeito de encapsulação de nutrientes dentro das estruturas da parede celular vegetal, as tornando inacessíveis ao aproveitamento pelos não ruminantes.

As quantidades desses carboidratos nos principais ingredientes utilizados para a formulação de rações para aves e suínos são variáveis. De acordo com Silva et al. (2016) a composição dos PNAs totais no milho e farelo de soja encontram-se em média de 8,00 e 27,00\%, respectivamente. Na Tabela 1, adaptada de Bach Knudsen (2001), encontram-se os valores percentuais de fibra e seus constituintes de alguns ingredientes utilizados na nutrição animal. Na Tabela 2 estão resumidos os principais carboidratos não digeridos por enzimas exógenas de animais não ruminantes e suas principais fontes alimentares.

Tabela 1: Conteúdo de amido, polissacarídeos não celulósicos, celulose, PNAs totais e lignina de alguns alimentos utilizados na alimentação animal.

\begin{tabular}{|c|c|c|c|c|c|c|}
\hline & \multirow{2}{*}{ Amido } & \multicolumn{2}{|c|}{ Polissacarídeo não celulósico } & \multirow{2}{*}{ Celulose } & \multirow{2}{*}{ PNAs Totais } & \multirow{2}{*}{ Lignina } \\
\hline & & Solúvel & Insolúvel & & & \\
\hline Milho & 69,00 & 0,90 & 6,60 & 2,20 & 9,70 & 1,10 \\
\hline Farelo de soja & 2,70 & 6,30 & 9,20 & 6,20 & 21,70 & 1,60 \\
\hline Farelo de Trigo & 22,20 & 2,90 & 27,30 & 7,20 & 37,40 & 7,50 \\
\hline Centeio & 61,30 & 4,20 & 9,40 & 1,60 & 15,20 & 2,10 \\
\hline Aveia com casca & 46,80 & 4,00 & 11,00 & 8,20 & 23,20 & 6,60 \\
\hline Aveia sem casca & 55,70 & 5,40 & 4,90 & 1,40 & 11,60 & 3,20 \\
\hline Farelo de canola & 1,80 & 5,50 & 12,30 & 5,20 & 22,00 & 13,40 \\
\hline Trigo & 65,10 & 2,50 & 7,40 & 2,00 & 11,90 & 1,90 \\
\hline
\end{tabular}

Fonte: Adaptado Bach Knudsen (2001).

\subsection{Carboidrases}

O início da utilização de enzimas, em nível industrial, começou há mais de 100 anos, segundo Pariza e Cook (2010), com a produção de $\alpha$-amilase a partir de fungos da espécie Aspergillus oryzae. O uso comercial de carboidrases iniciou-se nos finais da década de 1980 devido a capacidade de correção de problemas relacionados a umidade de cama, melhorias na digestibilidade e aumentos nos valores de energia metabolizável em dietas ricas em fibras (Raza et al., 2019). Khattak et al., (2006) e Messias (2014) relatam que estas proteínas utilizadas na alimentação animal são produzidas por micro-organismos específicos, geralmente bactérias das espécies Bacillus subtilis, Bacillus lentus, Bacillus amyloliquifaciens e Bacillus stearothermophils, os fungos Triochoderma longibrachiatum, Aspergillus oryzae e Aspergillus niger e a levedura Saccharomyces cerevisiae, através de processos fermentativos de onde é realizada extração e purificação.

As carboidrases são enzimas específicas para a degradação de carboidratos e sua utilização visa um incremento no aproveitamento de dietas que contenham ingredientes com grandes quantidades de PNAs (Koblitz, 2013; Romero et al. 2013). Estas proteínas são produzidas por fungos, algas, protozoários e sementes de plantas, sendo adicionados a ração com o objetivo 
de diminuir a viscosidade da dieta causada por esses polissacarídeos, melhorando, assim, a digestão de carboidratos estruturais (Carré, 2004; Paloheimo et al, 2011), aumentando também o acesso das enzimas endógenas ao conteúdo encapsulado dento da célula vegetal, os tornando disponíveis para o aproveitamento pelos animais (Choct, 2010; Cowieson, 2011). De acordo com Abreu (2017), as principais enzimas para a degradação de PNAs são as celulases, xilanases e betaglucases, estas não sendo sintetizadas endogicamente por animais não ruminantes. Outras enzimas como a manonase e alfa galactosidade também podem ser suplementadas. Na Tabela 3 são mostradas a principais carboidrases utilizadas na dieta de animais não ruminantes. $\mathrm{Na}$ Figura 1 é mostrada a distribuição da fibra em grãos e os sítios de ataque das enzimas carboidrases.

Figura 1: Distribuição da fibra em grão e os sítios de ataque das enzimas carboidrases.

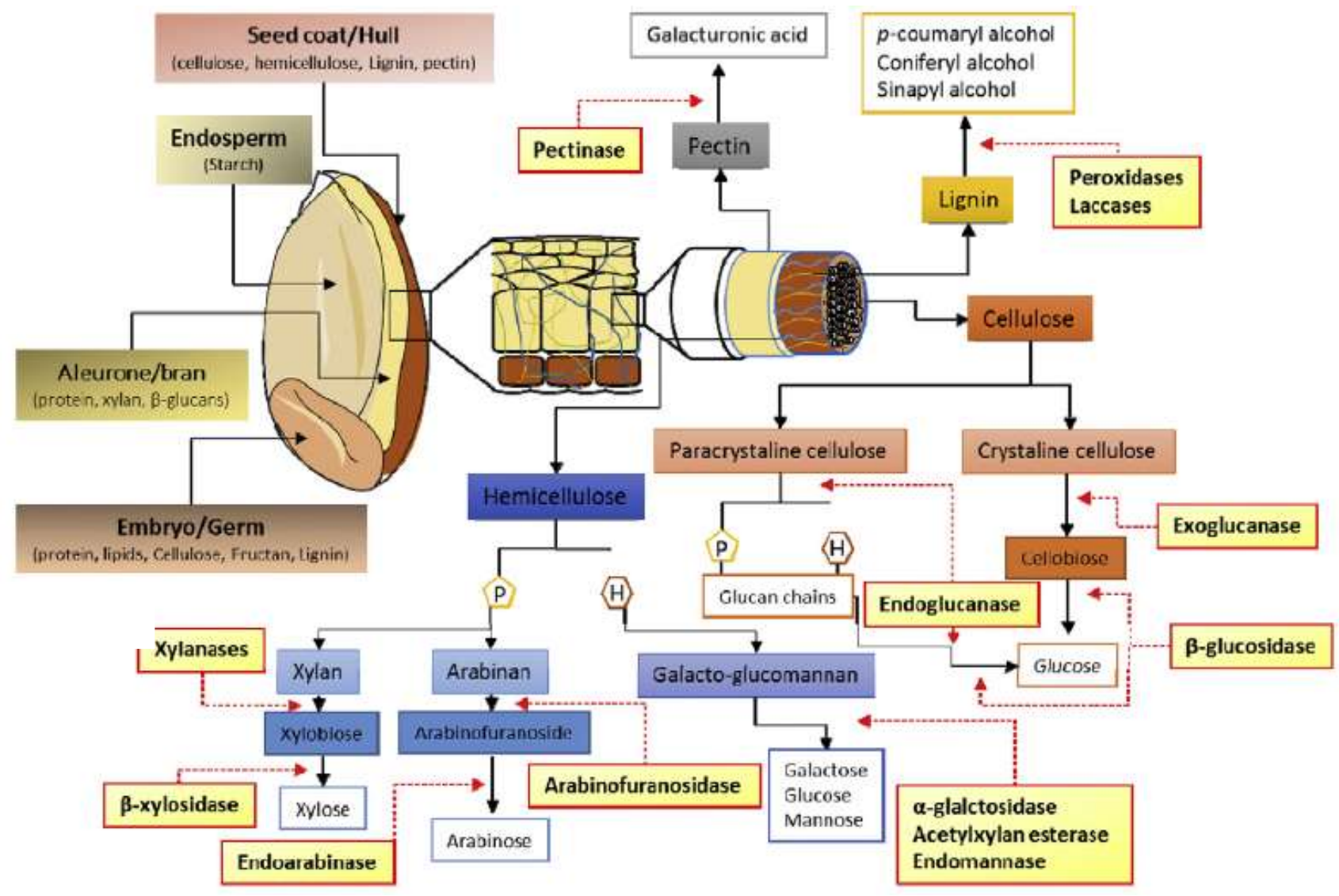

Fonte: Raza et al (2019).

Como observado na Tabela 1, a composição de PNAs são variáveis entre os diferentes ingredientes utilizados na alimentação de animais não ruminantes. Logo, o tipo de suplementação de carboidrases deve levar em consideração a formulação das rações que serão fornecidas. Em dietas em que se utilizará aveia e cevada, por exemplo, estas ricas em $\beta$ glucanos, a suplementação com $\beta$-glucanase melhoraria o aproveitamento destes alimentos. Já o trigo e o centeio, segundo Bedford (1995) e Choct (1997), possuem quantidades significativas de arabinoxilanos e que a adição de xilanase é mais ideal para estes ingredientes.

Segundo Opalinski et al. (2010) são observados melhorias na digestão e absorção de nutrientes, no trato gastrointestinal, quando se utiliza a suplementação de carboidrases. Esses efeitos são decorrentes da diminuição da viscosidade observada com a utilização dessas moléculas, levando a maior capacidade de digestão, aumento na taxa de passagem e menores conteúdos de água nas fezes e excretas dos animais. 
Adeola e Bedford (2004) relatam que os PNAs reduzem a capacidade de absorção de nutrientes devido ao impedimento de acesso das enzimas digestivas aos substratos presentes no alimento e que a suplementação de carboidrases tem a capacidade de melhorar o aproveitamento dos nutrientes energéticos da ração. Segundo Woyengo e Nyachoti (2011) devido as suas capacidades de hidrólise dos PNAs as carboidrases são produzidas comercialmente e são adicionadas as rações para melhorar a digestibilidade e aproveitamento dos nutrientes.

Diversos trabalhos com a utilização dessas enzimas e seus efeitos sobre o desempenho e saúde intestinal em suínos (Jiang et al., 2015; Pedersen et al., 2015; Clarke et al., 2018; Li et al., 2018; Li et al., 2020; Melo et al., 2020; Torres-Pitarch et al. 2020) e aves (Engberg et al. 2004; Apperson e Cherian, 2017; Yan et al., 2017. Roofchaei et al., 2019) já foram executados.

Tabela 2: polissacarídeo não digeridos por enzimas endógenas, seus resíduos manomérios e fontes alimentares.

Tipo de polissacarídeo

Polissacarídeos (Fibra dietética)

Amido resistente

Amido fisicamente inacessível

Glicose

Grânulos de amido resistente

Amido retrogrado

Glicose

Glicose

PNAs

Celulose

$\beta$-glucanos mistos ligados

Arabinoxilanas

Arabinogalactanas

Xiloglucanas

Ramnogalacturanas

Galactanas

Frutanas

Mananas

Pectina

Galactomananas

\section{Resíduos manométricos}

\section{Fonte alimentar}

Grão e sementes parcialmente moídos

Batata crua, banana

Produtos amiláceos termicamente tratados
Cereais e leguminosas

Aveia, cevada, arroz

Centeio, trigo, cevada

Co-produtos de cereais

Farelos de cereais

Casca de ervilha

Poupa de beterraba, farelo de sola

Arroz

Torta de coco

Maçã, polpa cítrica

Goma guar

\section{Oligosacarrídeos (prebióticos)}

Galactooligossacarídeos

Frutooligosscarídeos

Transgalactooligossacarídeos
Galactose, glicose, frutose

Frutose, glicose

Galactose, glicose
Farelo de soja, ervilha, farelo de canola

Cereais, aditivos alimentares

'Aditivo alimentar, produtos lácteos 


\subsection{Carboidrases e a saúde intestinal de aves}

A manutenção da saúde intestinal é um elemento essencial para uma produção sustentável e lucrativa visto que, segundo Yan et al. (2017), desordens na homeostase do intestino causam impactos em questões primordiais para a produção animal, tais como eficiência de produção, bem-estar animal, segurança alimentar e proteção do meio ambiente. Com a crescente limitação do uso de antibióticos promotores de crescimento na produção animal, o desenvolvimento e uso de outras estratégias nutricionais para a manutenção da integridade e saúde do intestino devem ser estudadas e desenvolvidas (Yan et al., 2017).

Os aditivos alimentares, tais como probióticos, prebióticos, simbióticos, enzimas exógenas, ácidos orgânicos e óleos essenciais já são estudados como alternativas para o uso dos antibacterianos (Pineda-Quiroga et al., 2017; Delmaschio et al. 2018; Dittoe et al., 2018).

Histologicamente, existem quatro camadas bem definidas na parede intestinal: mucosa (compreendendo os enterócitos ou células epiteliais, células endócrinas e outras), lâmina própria e a mucosa muscular, submucosa, muscular e serosa (Figura 2) (Klein, 2015). Esta organização é aplicável para a maioria dos vertebrados, no entanto, as aves não apresentam, em sua membrana osa, as pregas macroscópicas, denominadas vilosidades, observada nos mamíferos (Furlan et al., 2002). As células da mucosa do intestino estão em constante renovação. No geral ocorre a migração de células no interior das criptas para a extremidade das vilosidades, processo este que leva cerca de sete a dez dias em suínos com menos de três semanas de idade e de dois a cinco em animais com mais de 90 dias, sendo que é durante esta migração que ocorre a maturação do enterócito (Zlotowsk et al., 2008). Em aves este processo ocorre em cerca de três dias em pintos e em média de quatro em aves mais velhas (Uni, 2006; Smith et al., 2014).

Figura 2: estrutura da parede intestinal.

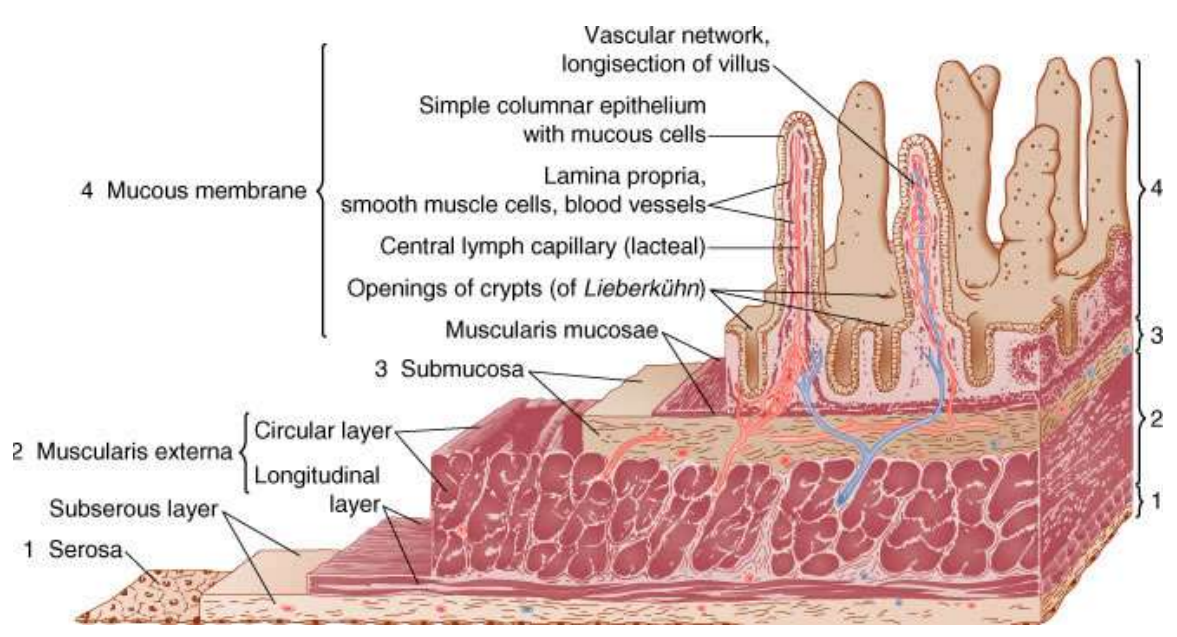

Fonte: https://www.misodor.com.br/ANATOFISIOINTDELGADO.php

O duodeno e jejuno, como primeira e segunda porção do intestino delgado, são os locais onde ocorrem a digestão e absorção dos nutrientes provenientes da dieta; e a área de superfície do trato gastrointestinal (TGI), bem como suas propriedades funcionais e de permeabilidade do epitélio, irão interferir na capacidade de absorção desta poção do sistema digestivo (Ferrer et al., 2003; Apperson \& Cherian, 2017; Westbrook \& Cherian, 2019). De modo geral, algumas características morfológicas, tais como a profundidade das criptas (PC) e altura de vilosidades (AV), são utilizadas como indicadores da capacidade absortiva do intestino e de seu estado de saúde (Santin et al., 2001; Baurhoo et al., 2007). Segundo Caspary (1992) e Uni et al. (2000) um incremento na densidade ou AV corresponderá em um maior número de enterócitos e 
células enteroendócrinas e está associado a uma maior expressão das enzimas da borda em escova, bem como melhorias nas funções digestivas e de absorção. A PC está relacionada com o processo de renovação das vilosidades e criptas mais profundas caracterizam renovação mais rápida do tecido epitélio intestinal (Yason et al., 1987). A relação altura de vilo:pronfundidade de cripta (AV:PC) é uma variável também utilizada para estimar a capacidade de digestiva do intestino, de modo que, de acordo com Montagne et al. (2003), alta relação AV:PC denotam mucosa intestinal com boa diferenciação e alta capacidade de digestão e absorção. Criptas mais profundas e vilosidades mais curtas estão associadas a má absorção intestinal, aumento da secreção pelo TGI e, assim, comprometimentos ao desempenho dos animais (Xu et al., 2003).

Tabela 3: Carboidrases utilizadas na alimentação de animais não ruminantes, seus micro-organismos produtores e funções.

\begin{tabular}{|c|c|c|c|}
\hline Enzima & Classificação & Organismo produtor & Função \\
\hline$\alpha$-amilase & Carboidrase & $\begin{array}{c}\text { Aspergillus spp., } \\
\text { Bacillus spp., } \\
\text { Rhizopus spp }\end{array}$ & Hidrolisa o amido \\
\hline$\alpha$-amilase maltogênica & Carboidrase & $\begin{array}{c}\text { Bacillus subtilis., } \\
\text { d-Bacillus stearothermophilus }\end{array}$ & $\begin{array}{l}\text { Hidrolisa o amido com } \\
\text { produção de maltose }\end{array}$ \\
\hline$\beta$-amilase & Carboidrase & Malte de cevada & $\begin{array}{l}\text { Hidrolisa o amido com } \\
\text { produção de maltose }\end{array}$ \\
\hline Celulase & Carboidrase & Aspergillus niger & Hidrolisa a celulose \\
\hline$\alpha$-Galactosidase & Carboidrase & $\begin{array}{l}\text { Aspergillus niger, } \\
\text { Morteirella vinaceae var } \\
\text { Saccharomyces sp }\end{array}$ & Hidrolisa oligossacarídeos \\
\hline$\beta$-Glucanase & Carboidrase & $\begin{array}{c}\text { Aspergillus spp., } \\
\text { Bacillus spp }\end{array}$ & Hidrolisa $\beta$-glucanos \\
\hline$\beta$-glucosidase & Carboidrase & Aspergillus niger & $\begin{array}{c}\text { Hidrolisa os produtos de } \\
\text { degradação da celulose em } \\
\text { glicose }\end{array}$ \\
\hline $\begin{array}{l}\text { Glucoamilase (amilo- } \\
\text { glucosidase) }\end{array}$ & Carboidrase & $\begin{array}{c}\text { Aspergillus niger, } \\
\text { Aspergillus oryzae, } \\
\text { Rhizopus niveus, } \\
\text { Rhizopus oryzae }\end{array}$ & $\begin{array}{l}\text { Hidrolisa o amido com } \\
\text { produção de glicose }\end{array}$ \\
\hline Hemicelulase & Carboidrase & $\begin{array}{c}\text { Aspergillus spp., } \\
\text { Bacillus spp., } \\
\text { Humicola sp., } \\
\text { Trichoderma sp. }\end{array}$ & Hidrolisa a hemicelulose \\
\hline Invertase & Carboidrase & Aspergillus niger, Saccharomyces sp & $\begin{array}{l}\text { Hidrolisa a sacarose em } \\
\text { glicose e frutose }\end{array}$ \\
\hline Lactase & Carboidrase & $\begin{array}{c}\text { Aspergillus niger, } \\
\text { Aspergillus oryzae, } \\
\text { Candida pseudotropicalis, } \\
\text { Kluyveromyces marxianis }\end{array}$ & $\begin{array}{l}\text { Hidrolisa a lactose em } \\
\text { glicose e galactose }\end{array}$ \\
\hline$\beta$-mananase & Carboidrase & $\begin{array}{c}\text { Aspergillus niger, } \\
\text { Bacillus lentus, } \\
\text { Trichoderma reeseic }\end{array}$ & Hidrolisa os $\beta$-mananos \\
\hline Pectinase & Carboidrase & $\begin{array}{c}\text { Aspergillus aculeatus, } \\
\text { Aspergillus niger, } \\
\text { Rhizopus oryzae }\end{array}$ & Hidrolisa a pectina \\
\hline Pululanase & Carboidrase & Bacillus acidopullulyticus & Hidrolisa o amido \\
\hline Xilanase & Carboidrase & $\begin{array}{c}\text { Aspergillus spp., } \\
\text { Bacillus spp., } \\
\text { Humicola sp., } \\
\text { Penicillum sp., } \\
\text { Trichoderma sp }\end{array}$ & Hidrolisa os xilanos \\
\hline
\end{tabular}

Adaptado: Munir e Maqsood (2013). 
Uma série de desafios a saúde e integridade intestinal, tais patógenos, falhas da digestão e na barreira da mucosa, disbacteriose, estresse oxidativo e inflamação podem comprometer a função desse segmento do trato digestivo (Yan et al., 2017). Estes pesquisadores ainda discutem que existem uma interação entre essas condições e que o desenvolvimento de uma pode predispor o animal a apresentarem outras o que, consequentemente, deterioraria a saúde geral do intestino.

O intestino das aves é colonizado por uma variedade de microorganismos, principalmente bactérias dos gêneros Lactobacillus spp., Bifidobacterium spp., Streptococcus spp., Bacterioides spp., Fusobacterium spp. e Eubacterium spp, em estado de equilíbrio e simbiose com os hospedeiro, exercendo funções importantes para a homeostase intestinal, tais como combate a patógenos oportunistas, renovação epitelial e melhor aproveitamento dos nutrientes ( $\mathrm{Li}$ et al., 2012; Apajalahti \& Vienola, 2016; Kogut, 2019). A disbacteriose é caracterizada por uma mudança na população de bactérias no intestino em favor daquelas que não são geralmente predominantes (Wilson et al., 2005). Esta mudança pode acarretar em problemas na função e saúde intestinal, levando a comprometimentos na digestibilidade dos alimentos, causados graças a lesões intestinais e encurtamento das vilosidades, além de favorecer a colonização de micro-organismos maléficos a saúde do animal (Biswas \& Kobayashi, 2013).

Além disso, o intestino é o órgão com maior vigilância imunológica do corpo devido à presença constante com antígenos e fornece, quando saudável, uma barreira para a entrada de micro-organismos e micotoxinas (Nishio \& Honda, 2012), sendo formada principalmente por membranas das células epiteliais, unidas por junções estreitas ou de oclusão (Figura 3) e uma camada de gel de muco que cobre o epitélio (Turner et al., 2006). As junções de oclusão são importantes reguladoras da permeabilidade paracelular do epitélio e processos de inflamação ou lesão resultam em comprometimentos na barreira com consequente aumento na absorção de bactérias e antígenos lumiais (Figura 4) (Bollard et al., 1995). Incrementos no peso no intestino delgado e ceco, em aves, podem ser observadas em situações de infecções parasitárias e consequentes desequilíbrios microbianos, devido ao espaçamento da parede da mucosa do intestino nestas situações (Figura 3) (Williams, 2005). A barreira intestinal modula a permeabilidade a antígenos e patógenos presentes no intestino, o que tem consequências sobre o sistema de defesa do animal e este processo regula a partição de energia entre aquela que irá ser direcionada ao crescimento e desempenho animal e a que vai manter a homeostase do sistema imunológico (Huntley et al., 2018). Logo, quaisquer fatores que afetem a integridade desta barreira irão comprometer o desempenho.

Os PNAs causam diversos comprometimentos trânsito intestinal, digestibilidade, absorção dos nutrientes modificações na estrutura e função do TGI e saúde intestinal de animais não ruminantes (Dworkin et al., 1976). Estes carboidratos causam aumento da viscosidade do trato gastrointestinal, diminuem a taxa de passagem, comprometendo, assim, a digestão de nutrientes, graças a baixa dissociação de substratos e enzimas, impedimento das interações necessárias para a digestão e absorção na superfície da mucosa intestinal e afetando a liberação de hormônios intestinais tais como a Colecistoquinina (CKK), Peptídeo semelhante ao glucagon (GLP-1) e Peptídeo YY, além de interferirem, também, na microbiota entérica, causando disbacteriose (Choct, 2001; Choct et al., 2004; Cummings \& Overduin, 2007; Wanders et al., 2011). Como alternativa, a suplementação de carboidrases tem sido utilizada com modo para minimizar os efeitos negativos desses polímeros aumentando a taxa de difusão de nutrientes do lúmen para a corrente sanguínea (Bach Knudsen, 2001; Delmaschio et al., 2018). Estas enzimas atuam na redução da viscosidade e outros efeitos negativos através da degradação dos PNAs, além de graças a sua ação sobre a parede celular, melhorarem o acesso das enzimas endógenas ao conteúdo presente no interior das células vegetais. Todos esses efeitos somados proporcionam melhor digestibilidade e menor teor de umidade nas excretas de aves (Brito et al., 2008).

Apperson e Cherian (2017), estudaram a adição de semente de linhaça (SL) em níveis de 10 a 15\% mais suplementação de um mix de carboidrases (celulase, xilanase, glucanase, manonase e galactamase), verificaram que as enzimas mais $10 \%$ de SL, proporcionaram, aos 22 dias de idade, aumentos na altura e largura das vilosidades, bem como na 
profundidade de cripta do duodeno e jejuno de frangos de corte. Os autores discutem que, além das características citadas previamente, a largura dos vilos também está estritamente relacionada a capacidade de absorção do intestino, de modo que vilosidades mais largas denotam em melhorias na absorção de nutrientes, concluindo que as enzimas foram eficazes, em dietas com a presença da SL, em proporcionar melhor saúde intestinal para a aves. Yan et al. (2017), investigando a utilização de centeio, trigo e farinha de penas com ou não a suplementação de carboidrases e protease na alimentação de frangos de corte, observaram que, nas dietas onde não houve a adição das enzimas que digerem carboidratos, a viscosidade da digesta e a contagem de Clostridium perfringens no intestino delgado foi superior, aos 22 dias e 15 dias de idade, respectivamente, em comparação as rações onde o complexo a base de xilanase, galactosidase e glucanase estava presente. Além disso, houve maior infiltração linfocitária na mucosa do intestino delgado nas aves que receberam alimentação sem as enzimas e que a presença das carboidrases atenuaram esta característica. A maior viscosidade da dieta, segundo discussão dos pesquisadores, diminuiu o trânsito intestinal, impediu o contato das enzimas endógenas e seus substratos, bem como criou uma barreira para a absorção dos nutrientes pelos enterócitos, isto somado a problemas relacionados a inflamação e consequentes comprometimentos na saúde intestinal, causada pelos PNAs, levou a menor aproveitamento de todos os nutrientes, especialmente gorduras e outros compostos solúveis em lipídeos, tais como carotenos e vitaminas lipossolúveis, visto que as concentrações de vitamina E no fígado, zoaxatina e luteína plasmática foram baixas nas aves que receberam as rações sem as enzimas. As carboidrases atenuaram, significativamente, todos esses efeitos negativos.

Figura 3: célula epitelial com demonstração da junção estreita ou de oclusão.

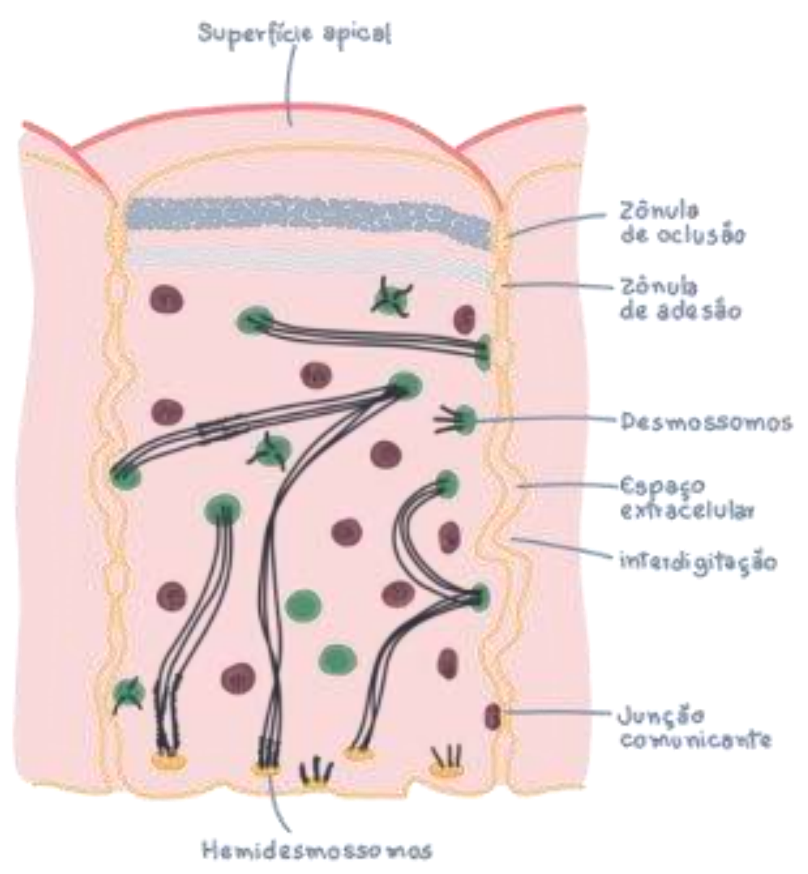

Fonte: https://www.google.com/ 
Figura 4: junções estreitas em situação normal e inflamação.

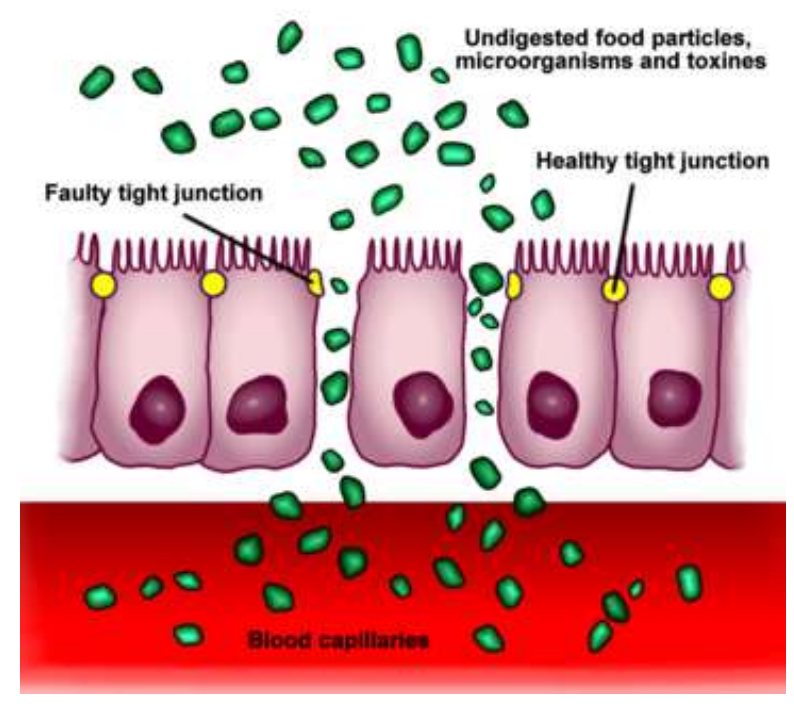

Fonte: https://www.google.com/

Liu et al. (2012), encontraram que a xilanase, quando adicionada a ração a base de trigo para frangos de corte, não teve influência sobre a AV e PC do duodeno, jejuno e íleo, mas teve a capacidade de aumentar a relação V:C no jejuno. Roofchaet et al. (2019) observaram que a combinação de xilanase com fitase ou acidificante aumentou o comprimento das vilosidades do jejuno de frangos de corte, não sendo encontradas diferenças para as demais variáveis de morfometria intestinal. Os pesquisadores não apresentaram informações sobre como a interação desses componentes poderiam influenciar em tal característica.

Wang et al. (2005) verificaram que a suplementação com níveis crescentes $(0,200,400,600,800$ e $1000 \mathrm{mg} / \mathrm{kg}) \mathrm{de}$ uma preparação de carboidrases contendo xilanase, $\beta$-glucanase, celulase e pectinase, em dietas a base de trigo, proporcionou diminuição no comprimento relativo do intestino anterior (duodeno e jejuno), íleo e ceco nos 21 e 42 dias de idade de frangos de corte. $\mathrm{O}$ peso do pâncreas e fígado, tanto na fase de crescimento, quanto na de terminação, foram também diminuídos linearmente com a adição das enzimas. De acordo com os pesquisadores, na presença de PNAs, com seus efeitos negativos sobre o trânsito intestinal e digestão de nutrientes, o intestino se adapta potencializando os seus mecanismos secretores devido ao incremento na necessidade de enzimas digestivas, já que se eleva a quantidade de substrato não digerido, desencadeando, assim, aumentos no tamanho do TGI e glândulas anexas. As carboidrases, ao degradarem os PNAs, eliminam esses efeitos e melhoram as condições fisiológicas e de saúde do intestino.

Westbrook e Cherian (2019) verificaram efeitos mínimos da suplementação de uma mistura multicarboidrases (celulase, xilanase, glucanase, mamanase, galactomanase e amilase), em dietas com SL, sobres a morfometria intestinal (AV, PV, LV, PC e AV:PC) em galinhas poedeiras quando comparado os resultados do tratamento apenas com a SL. No entanto, os autores comentam que as rações onde as enzimas estavam presentes proporcionaram uma vantagem comparativa sobre a dieta controle, melhorando a estado de saúde intestinal, visto que proporcionaram aumentos na AV e LV do duodeno e jejuno e a relação AV:PC no jejuno, estas características estando associadas a melhor capacidade de absorção.

Jasim e Fadel (2020) não encontraram diferenças na morfometria intestinal (comprimento e peso do intestino, AV e PC) de galinhas poedeiras Lohman Brown, alimentadas com dietas a base de milho, farelo de soja e trigo suplementadas com um complexo de carboidrases contendo xilanase, glucanase e amilase, sozinho ou em combinação com probiótico. Os pesquisadores atribuíram os aumentos nessas características, nos animais que receberam ambos os aditivos, exclusivamente ao probiótico, já que o mesmo, sozinho, teve a capacidade de incrementá-las. 
Grecco et al. (2019a) estudando a utilização de dois tipos de xilanase (A: 1.500 EPU/kg de atividade mais ação adicional de ação suplementar de celulase, $\beta$-glucanase e $\alpha$-amilase e protease; B: 16.000 BXU/kg de atividade mínima), observaram que as enzimas A proporcionou aumentou a AV e relação AV:PC do jejuno de codornas de corte (Coturnix coturnix sp.) com 15 dias de idade, mas não tiveram diferenças entre si. Já Grecco et al. (2019b), em extensão do trabalho, verificaram que a utilização de uma xilanase com 1.500 EPU/kg de atividade e ação suplementar de celulase, $\beta$-glucanase e $\alpha$ amilase foi capaz de melhorar a AV:PC de codornas de corte com 35 dias de idade. Em ambos os trabalhos os pesquisadores discutem que estas características denotam melhor desenvolvimento, capacidade de absorção e saúde do intestino.

Silva et al. (2018) utilizando suplementação de xilanse e $\beta$-glucanase para codornas japonesas (Coturnix coturnix japônica) alimentadas com bagaço de laranja desidratado, não encontraram alteração no comprimento do proventrículo, moela, fígado, pâncreas e intestino delgado, mas verificaram que a presença das enzimas aumentou o peso total do TGI das aves. Os autores discutem que estes resultados são contrários ao que se observa normalmente na literatura, onde a utilização de carboidrases causa uma diminuição no tamanho total do TGI devido ao melhor aproveitamento dos PNAs e abrandaria a resposta secretora das glândulas anexas e outros segmentos do sistema digestivo.

Yan et al. (2017) observaram redução na contagem ileial de Clostridium perfringens no íleo de frangos de corte alimentados com dietas a base de centeio, trigo e farinha de penas com suplementação de carboidrases. Os autores argumentam que a diminuição observada na contagem desta espécie de bactéria nessa porção do intestino, com a utilização dessas enzimas, em comparação a dieta controle sem as mesmas, demonstra ocapacidade de certos ingredientes em alterar a população microbiana do desse segmento do TGI e que o uso de estratégias para o melhor aproveitamento e degradação de determinados componentes desses alimentos pode ser uma alternativa para contornar este problema. A C. perfringens é uma bactéria do tipo gram-negativa encontrada como habitante normal do intestino de aves, no entanto, em situações desequilíbrio na microbiota intestinal, onde se observa aumentos de sua população, mais outros fatores tais como coccidiose, micotoxicose e Salmonelose, há risco de desenvolvimento de enterite necrótica nos animais (Guo et al., 2017), além de também promover o crescimento excessivo de bactérias gram-negativas, como a Escherichia coli, e consequentes aumentos na concentração de endotoxinas na corrente sanguínea e bactérias no fígado e baço (Liu et al., 2010). Alguns trabalhos já tem demonstrado que a administração de rações com grandes quantidades cevada e trigo, estes ricos em PNAs, aumentam a incidência de enterite necrótica em aves (Engberg et al. 2004).

Liu et al. (2012) encontraram que a xilase, em dietas a base de trigo, teve um papel preponderante na atenuação dos efeitos negativos do desafio de $C$. perfrigens e que melhorou a função da barreira intestinal e consequente desempenho de frangos de corte da linhagem Ross 308. Os autores atribuem esses resultados a suplementação da enzima e sua ação sobre os arabinoxilanos, produzindo como produtos xilose e xilo-oligômeros que apresentaram função semelhante aos prebióticos, tendo como resultado a facilitação da proliferação de bactérias intestinais benéficas como Bifidobacterium e Lactobacillus que impediram o crescimento de micro-organismos patogênicos. Outros trabalhos, como o de Kiarie et al. (2007), Bach Knudsen (2014) e Lee et al. (2017) tem confirmado estes efeitos. Além disso a utilização de carboidrases, em dietas apresentando ingredientes com grandes quantidades de PNAs, limita a quantidade de substrato no íleo, o que tem como resultado uma menor atividade microbiana (Choct et al., 1999).

Bozkurt et al. (2014) verificaram que a utilização de um complexo enzimático contento carboidrases (celulase, xilanase, $\beta$-glucanase e mananase) e protease, assim como outros aditivos, em substituição aos coccidianos tradicionais, teve a capacidade de diminuir as lesões intestinais de frangos de corte desafiados com Eimeria spp. devido ao impedimento do crescimento de bactérias patogênicas, o que inibiu a penetração de oocistos do protozoário através do epitélio do intestino. Os pesquisadores concluem que as enzimas foram eficazes em diminuiu as consequências da coccidiose induzida via infecção 
experimental e que, além dos efeitos sobre a saúde intestinal, melhorou também o crescimento e eficiência alimentar dos animais.

Craig et al. (2020) investigando o efeito da utilização de carboidrases (xilanase e $\beta$-glucanase) e prebióticos para frangos de corte alimentados com mix de cereais (farelo e gérmen de trigo, milho e soja) desafiados com coccidiose, não encontraram efeito das enzimas sobre a contagem de oocitos coccidianos no TGI dos animais, mas estas foram capazes de diminuir a quantidades de arabinose solúvel e xilose insolúvel no íleo dos mesmos.

Jia et al. (2009) estudaram a utilização de um complexo multi-carboidrase (celulase, pectinase, xilanase, glucamase, mananase e galactomase) em frangos de corte em dietas a base de milho e trigo, não encontrou diferenças na contagem de $C$. perfrigens e escore de lesão do intestino, no entanto a suplementação enzimática, nas rações com trigo, minimizou os efeitos negativos no desempenho observado nos animais desafiados com a bactéria. Roofchaei et al. (2019) observaram efeito inibitório no crescimento de $E$. coli no íleo de frangos de corte alimentados com xilanase combinada com a fitase. Lei et al. (2018) perceberam aumento linear na concentração de bactérias lácticas, mas não encontrou diferenças nas quantidades de coliformes e Salmonella, quando suplementou níveis crescentes de xilanase (0, 225245 e 900 U/kg) em rações a base de milho, farelo de soja e trigo, nas excretas de galinhas poedeiras da linhagem Hy Line Brown. Estes trabalhos demonstram que, como já foi discutido previamente, a capacidade das carboidrases em modular a população microbiana no intestino em favor de bactérias benéficas. Outros estudos, com efeitos semelhantes, já foram conduzidos (Bedford \& Cowieson, 2012; Munyaka et al., 2016).

Wang et al. (2005) observaram aumento linear nas quantidades de ácidos graxos de cadeia curta (AGCC) no ceco de frangos de corte alimentados com níveis crescentes de um mix de carboidrases devido a incapacidade dos micro-organismos presentes no intestino posterior em fermentar as grandes moléculas de PNAs e que a viscosidade proporcionada por estes carboidratos dificulta a entrada de componentes não digeridos no cécum. A suplementação de carboidrases, ao degradarem esses polissacarídeos em compostos de menor peso molecular, proporcionariam menor viscosidade, melhoraria a digestibilidade dos nutrientes e os componentes não aproveitados, com função prebiótica, poderiam entrar no ceco aumentando a produção de AGCC devido ao aumento na contagem microbiana benéfica.

Diante do exposto podemos concluir que o uso de enzimas carboidrases possui efeito benéfico sobre a saúde intestinal das aves, visto que, estes aditivos, ao degradarem os PNAs, atenuam os efeitos destes carboidratos sobre a viscosidade intestinal, melhorando a digestibilidade de nutrientes, promovendo melhorias nas características morfométricas e atuando também na modulação da população microbiana do intestino.

\section{Considerações Finais}

Com a crescente limitação do uso de antibióticos na nutrição animal, a busca por alternativas alimentares que visem a manutenção da saúde intestinal de aves e suínos já é uma realidade. Neste contexto, o uso de enzimas exógenas, dentre elas as carboidrases, exercem efeitos positivos sobre a morfometria intestinal, no estado imunológico e microbiano do intestino, com consequências positivas sobre a saúde e desempenho das aves.

\section{Referências}

Abreu, J. A. D. C. (2017). Dissertação de Mestrado. Adição combinada de carboidrases e óleos essenciais em dietas de novilhos confinados.

Adeola, O. \& Bedford, M. R. (2004). Exogenous dietary xylanase ameliorates viscosity-induced anti-nutritional effects in wheat-based diets for White Pekin ducks (Anas platyrinchos domesticus). British Journal of Nutrition, 92 (1), 87-94.

Anwar, M. I., Muhammad, F., Awais, M. M., \& Akhtar, M. (2017). A review of $\beta$-glucans as a growth promoter and antibiotic alternative against enteric pathogens in poultry. World's Poultry Science Journal, 73 (3), 651-661. 
Apajalahti, J. \& Vienola, K. (2016). Interaction between chicken intestinal microbiota and protein digestion. Animal Feed Science and Technology, 221 (2016), 323-330.

Apperson, K. D. \& Cherian, G. (2017). Effect of whole flax seed and carbohydrase enzymes on gastrointestinal morphology, muscle fatty acids, and production performance in broiler chickens. Poultry Science, 96 (5), 1228-1234.

Bach Knudsen, K.E. (2001). The nutritional significance of "dietary fibre” analysis. Animal Feed Science and Technology, 90 (1-2), 3-20.

Bach Knudsen, K. E. (2014). Fiber and nonstarch polysaccharide content and variation in common crops used in broiler diets. Poultry Science, 93 (9), 2380 2393.

Baurhoo, B., Phillip, L. \& Ruiz-Feria, C. A. (2007). Effects of purified lignin and mannan oligosaccharides on intestinal integrity and microbial populations in the ceca and litter of broiler chickens. Poultry Science, 86 (6), 1070-1078.

Bederska-Łojewska, D., Swiątkiewicz, S., Arczewska-Włosek, A. \& Schwarz, T. (2017). Rye non-starch polysaccharides: their impact on poultry intestinal physiology, nutrients digestibility and performance indices-a review. Annals of Animal Science, 17 (2), 351-369.

Bedford, M. R. (1995). Mechanism of action and potential environmental benefits from the use of feed enzymes. Animal Feed Science and Technology, 53 (2), $145-155$.

Bedford, M. \& Cowieson, A. J. (2012). Exogenous enzymes and their effects on intestinal microbiology. Animal Feed Science and Technology, 173(1-2), 7685 .

Biswas, A. \& Kobayashi, K. S. Regulation of intestinal microbiota by the NLR protein family. International Immunology, 25 (4), $207-214$.

Bozkurt, M., Aysul, N., Küçükyilmaz, K., Aypak, S., Ege, G., Catli, A. U. \& Çinar, M. Efficacy of in-feed preparations of an anticoccidial, multienzyme, prebiotic, probiotic, and herbal essential oil mixture in healthy and Eimeria spp.-infected broilers. Poultry Science, 93 (2), $389-399$.

Carré, B. Causes for variation in digestibility of starch among feedstuffs. Poultry Science, v.60 (1), 76-89.

Caspary, W.F. 1992. Physiology and pathophysiology of intestinal absorption. The American Journal of Clinical Nutrition, 55 (2) $299-308$.

Cheng, Y., Chen, Y., Li, J., Qu, H., Zhao, Y., Wen, C. \& Zhou, Y. Dietary $\beta$-Sitosterol improves growth performance, meat quality, antioxidant status, and mitochondrial biogenesis of breast muscle in broilers. Animals, 9 (3), 71-83.

Choct, M., Hughes, R. J., Wang, J., Bedford, M. R., Morgan, A. J. \& Annison, G. Increased small intestinal fermentation is partly responsible for the anti-nutritive activity of non-starch polysaccharides in chickens. British Poultry Science, 37 (3), 609-621.

Choct, M. Feed non-starch polysaccharides: chemical structures and nutritional significance. Feed Milling International, 191 (6), 13 -26.

Choct, M, Hughes, R. J. \& Bedford, M. R. Effects of a xylanase on individual bird variation, starch digestion throughout the intestine, and ileal and caecal volatile fatty acid production in chickens fed wheat. British Poultry Science, 40 (3), 419-422.

Choct, M. 2001. Enzyme supplementation of poultry diets based on viscous cereals. Enzymes in Farm Animal Nutrition. Book.

Choct, M., Kocher, A., Waters, D. L. E., Pettersson, D. \& Ross, G. A comparison of three xylanases on the nutritive value of two wheats for broiler chickens. British Journal of Nutrition, v.92 (1), 53-61.

Choct, M. Feed polysaccharides: nutritional roles and effect of enzymes. 2010. In: IV Congresso Latino Americano de Nutrição Animal - IV CLANA, 65-78.

Cowieson, A. J., Wilcock, P., \& Bedford, M. R. Super-dosing effects of phytase in poultry and other monogastrics. World's Poultry Science Journal, 67 (2), $225-236$.

Craig, A. D., Khattak, F., Hastie, P., Bedford, M. R. \& Olukosi, O. A. The similarity of the effect of carbohydrase or prebiotic supplementation in broilers aged 21 days, fed mixed cereal diets and challenged with coccidiosis infection. Plos One, 15 (2), e0229281.

Cummings, D. E. \& Overduin, J. V. Gastrointestinal regulation of food intake. The Journal of Clinical Investigation, 117 (1), $13-23$.

Delmaschio, I. Enzimas na alimentação de animais monogástricos-revisão de literatura. Revista Científica de Medicina Veterinária-UNORP, 2 (1), 6-20.

Dittoe, D. K., Ricke, S. C. \& Kiess, A. S. Organic acids and potential for modifying the avian gastrointestinal tract and reducing pathogens and disease. Frontiers in Veterinary Science, v.5 (1), 216-228.

Dworkin, L. D., Levine, G. M., Farber, N. J. \& Spector, M. H. Small intestinal mass of the rat is partially determined by indirect effects of intraluminal nutrition. Gastroenterology, 71 (4), 626-630.

Engberg, R. M., Hedemann, M. S., Steenfeldt, S. \& Jensen, B. B. Influence of whole wheat and xylanase on broiler performance and microbial composition and activity in the digestive tract. Poultry Science, 83 (6), 925-938.

Ferreira, C. B., Geraldo, A., Vieira Filho, J. A., Brito, J. Á. G. D., Bertechini, A. G. \& Pinheiro, S. R. F. Associação de carboidrases e fitase em dietas valorizadas e seus efeitos sobre desempenho e qualidade dos ovos de poedeiras leves. Arquivo Brasileiro de Medicina Veterinária e Zootecnia, 67 (1), 249254.

Ferrer, C., Pedragosa, E., Torras-Llort, M., Parcerisa, X., Rafecas, M., Ferrer, R. \& Moreto, M. Dietary lipids modify brush border membrane composition and nutrient transport in chicken small intestine. The Journal of Nutrition, 133 (4), 1147-1153. 
Fireman, F. A. T. \& Fireman, A. K. B. A. T. Enzimas na alimentação de suínos. Ciência Rural, 28 (1), 173-178.

Fortes, B. D. A., Café, M. B., Stringhini, J. H., Brito, J. Á. G., Rezende, P. L. D. P. \& Silva, R. D. Avaliação de programas nutricionais com a utilização de carboidrases e fitase em rações de frangos de corte. Ciência Animal Brasileira, 13 (1), 24-32.

Furlan, R. L., Macari, M. \& Sugeta, S. M. (2002). Fisiologia aviária aplicada a frangos de corte. Book.

Grecco, E. T., Marcato, S. M., Oliveira, T. M. M., Stanquevis, C. E., Grieser, D. O., Perine, T. P. \& Benites, M. I. Effects of the Dietary Inclusion of Xylanase on the Performance and Jejunum Morphometry of Meat-Type Quails. Brazilian Journal of Poultry Science, 21 (4), 1-8.

Grecco, É. T., Marcato, S. M., Oliveira-Bruxel, T. M. D., Stanquevis, C. E., Grieser, D. D. O., Finco, E. M. \& Ferreira, M. F. Z. Xylanase for meat-type quails from 15 to 35 days old. Revista Brasileira de Zootecnia, 48 (1), e20180252.

Guo, S., Liu, D., Zhang, B., Li, Z., Li, Y., Ding, B. \& Guo, Y. Two Lactobacillus species inhibit the growth and $\alpha$-toxin production of Clostridium perfringens and induced proinflammatory factors in chicken intestinal epithelial cells in vitro. Frontiers in Microbiology, 8 (1), $2081-2093$.

Huntley, N. F., Nyachoti, C. M. \& Patience, J. F. Lipopolysaccharide immune stimulation but not $\beta$-mannanase supplementation affects maintenance energy requirements in young weaned pigs. Journal of Animal Science and Biotechnology, 9 (1), 47-61.

Jasim, M. S., Fadel, G. Y. Effect of feed supplementation of probiotic and digestive enzymes in production performance and intestinal biometrics of laying hens. Plant Archives, 20 (1), 1773-1781.

Jha, R. \& Berrocoso, J. D. Dietary fiber utilization and its effects on physiological functions and gut health of swine. Animal, 9 (9), $1441-1452$.

Jia, W., Slominski, B. A., Bruce, H. L., Blank, G., Crow, G., \& Jones, O. Effects of diet type and enzyme addition on growth performance and gut health of broiler chickens during subclinical Clostridium perfringens challenge. Poultry Science, 88(1), 132-140.

Khattak, F. M., Pasha, T. N., Hayat, Z. \& Mahmud, A. Enzymes in poultry nutrition. Journal of Animal Poultry Science, 16 (1-2), 1-7.

Kiarie, E., Nyachoti, C. M., Slominski, B. A. \& Blank, G. Growth performance, gastrointestinal microbial activity, and nutrient digestibility in early-weaned pigs fed diets containing flaxseed and carbohydrase enzyme. Journal of Animal Science, 85 (11), 2982-2993.

Klein, B. G. (2015). Cunningham Tratado de Fisiologia Veterinária. Book.

Koblitz, M. G. B. (2013). Bioquímica de alimentos: teoria e aplicações práticas. Book.

Kogut, M. H. 2019. The effect of microbiome modulation on the intestinal health of poultry. Animal Feed Science and Technology, 250 (2019), 32-40.

Lee, S. A., Wiseman, J., Masey O’Neill, H. V., Scholey, D. V., Burton, E. J. \& Hill, S. E. Understanding the direct and indirect mechanisms of xylanase action on starch digestion in broilers. Journal of World's Poultry Research, 7 (2), 35-47.

Lei, X. J., Lee, K. Y. \& Kim, I. H. Performance, egg quality, nutrient digestibility, and excreta microbiota shedding in laying hens fed corn-soybean-mealwheat-based diets supplemented with xylanase. Poultry Science, 97(6), 2071-2077.

Li, K., Bihan, M.,, Yooseph, S., \& Methe, B. A. . Analyses of the microbial diversity across the human microbiome. Plos One, 7 (6), e32118.

Liu, D., Guo, Y., Wang, Z. \& Yuan, J. Exogenous lysozyme influences Clostridium perfringens colonization and intestinal barrier function in broiler chickens. Avian Pathology, 39 (1), 17-24.

Liu, D., Guo, S., \& Guo, Y. Xylanase supplementation to a wheat-based diet alleviated the intestinal mucosal barrier impairment of broiler chickens challenged by Clostridium perfringens. Avian Pathology, 41 (3), 291-298.

Montagne, L., Pluske, J. R. \& Hampson, D. J. A review of interactions between dietary fibre and the intestinal mucosa, and their consequences on digestive health in young non-ruminant animals. Animal Feed Science and Technology, 108 (1-4), 95-117.

Munyaka, P. M., Nandha, N. K., Kiarie, E., Nyachoti, C. M. \& Khafipour, E. Impact of combined $\beta$-glucanase and xylanase enzymes on growth performance, nutrients utilization and gut microbiota in broiler chickens fed corn or wheat-based diets. Poultry Science, 95(3), 528-540.

Nishio, J., Honda, K. Immunoregulation by the gut microbiota. Cellular and Molecular Life Sciences, 69 (21), 3635-3650.

Nitrayová, S., Heger, J., Patráš, P., Kluge, H. \& Brož, J. Effect of xylanase on apparent ileal and total tract digestibility of nutrients and energy of rye in young pigs. Archives of Animal Nutrition, 63 (4), 281-291.

Opalinski, M., Maiorka, A., Cunha, F. D., Rocha, C. D. \& Borges, S. A. Adição de complexo enzimático e da granulometria da soja integral desativada melhora desempenho de frangos de corte. Ciência Rural, 40 (3), 628-632.

Paloheimo, M., Bedford, M.R. \& Partridge, G.G. (2011). Xylanases and Cellulases as Feed Additives Enzymes in Farm Animal Nutricion. Book.

Pariza, M. W. \& Cook, M. Determining the safety of enzymes used in animal feed. Regulatory Toxicology and Pharmacology, 56 (3), $332-342$.

Pineda-Quiroga, C., Atxaerandio, R., Zubiria, I., gonzalez-pozuelo, I., Hurtado, A., Ruiz, R. \& Garcia-Rodriguez, A. Productive performance and cecal microbial counts of floor housed laying hens supplemented with dry whey powder alone or combined with Pediococcus acidilactici in the late phase of production. Livestock Science, 195 (1), 9-12.

Raza, A., Bashir, S. \& Tabassum, R. An update on carbohydrases: growth performance and intestinal health of poultry. Heliyon, 5 (4), e01437, 2019. 
Romero, L. F., Parsons, C. M., Utterback, P. L., Plumstead, P. W. \& Ravindran, V. Comparative effects of dietary carbohydrases without or with protease on the ileal digestibility of energy and amino acids and AMEn in young broilers. Animal Feed Science and Technology, 181 (1-4), 35-44.

Roofchaei, A., Rezaeipour, V., Vatandour, S. \& Zaefarian, F. Influence of dietary carbohydrases, individually or in combination with phytase or an acidifier, on performance, gut morphology and microbial population in broiler chickens fed a wheat-based diet. Animal Nutrition, 5 (1), 63-67.

Santin, E., Maiorka, A., Macari, M., Grecco, M., Sanchez, J. C., Okada, T. M. \& Myasaka, A. M. Performance and intestinal mucosa development of broiler chickens fed diets containing Saccharomyces cerevisiae cell wall. Journal of Applied Poultry Research, 10 (3), $236-244$.

Silva, D. M., Rodrigues, D. R., Gouveia, A. B. V. S., Mesquita, S. A., Santos, F. R. \& Minafra, C. S. Carboidrases em rações de frangos de corte. PUBVET, v.10 (11), 795-872.

Silva, S. A. A., De Paulo, L. M., Silva, N. G. D., Gouveia, A. B. V. S., Sampaio, S. A., Santos, F. R. \& Minafra, C. S. (2018). Dehydrated Orange pomace and carbohydrates in the diet of Japanese quails on the biometrics of the gastrointestinal tract. In $55^{\mathrm{a}}$ Reunião Anual da Sociedade Brasileira de Zootecnia, $28^{\circ}$ Congresso Brasileiro de Zootecnia. Abstract.

Smith, A. L., Powers, C. \& Beal, R. K. (2014) The avian enteric immune system in health and disease. Avian Immunology. Book.

Smits, C. H. \& Annison, G. Non-starch plant polysaccharides in broiler nutrition-towards a physiologically valid approach to their determination. World's Poultry Science Journal, 52 (2), 203-221.

Tahir, M., Saleh, F., Ohtsuka, A. \& Hayashi, K. An effective combination of carbohydrases that enables reduction of dietary protein in broilers: Importance of hemicellulase. Poultry Science, 87 (4), 713-718.

Tavernari, F. C., Carvalho, T. A., Assis, A. P. \& Lima, H. J. D. Polissacarídeos não-amiláceo solúvel na dieta de suínos e aves. Revista eletrônica Nutritime, 5 (5), 673-689.

Uni, Z., Zaiger, G., Gal-Garber, O., Pines, M., Rozenboim, I. \& Reifen, R. Vitamin A deficiency interferes with proliferation and maturation of cells in the chicken small intestine. British Poultry Science, 41 (4), 410-415.

Uni, Z. (2006). Early development of small intestinal function. Avian Gut Function in Health and Fisease. Book.

Vahjen, W., Osswald, T., Schäfer, K. \& Simon, O. Comparison of a xylanase and a complex of non starch polysaccharide-degrading enzymes with regard to performance and bacterial metabolism in weaned piglets. Archives of Animal Nutrition, 61 (2), 90-102.

Van Soest, P. J., Robertson, J. B. \& Lewis, B. A. Methods for dietary fiber, neutral detergent fiber and nonstarch polysaccharides in relation to animal nutrition. Journal of Dairy Science, v.74 (10), 3583-3597.

Vargas, R. C., Geraldo, A., Rocha, T. C., Silva, I. M., Teles, S. P., Nogueira, F. S. \& Gonçalves, R. A. (2017). Multi-enzyme complex in laying hens diet. Revista de Ciências Agroveterinárias, 16 (1), 61-69.

Wagner, D. D. \& Thomas, O. P. Influence of diets containing rye or pectin on the intestinal flora of chicks. Poultry Science, 57 (4), $971-975$.

Wanders, A. J., Van Den Borne, J. J., De Graaf, C., HulshoF, T., Jonathan, M. C., Kristensen, M. \& Feskens, E. J. Effects of dietary fibre on subjective appetite, energy intake and body weight: a systematic review of randomized controlled trials. Obesity Reviews, 12 (9), $724-739$.

Wang, Z. R., Qiao, S. Y., Lu, W. Q. \& Li, D. F. Effects of enzyme supplementation on performance, nutrient digestibility, gastrointestinal morphology, and volatile fatty acid profiles in the hindgut of broilers fed wheat-based diets. Poultry Science, 84 (6), 875-881.

Warpechowski, M. B. (1996). Dissertação de Mestrado. Efeito da fibra insolúvel da dieta sobre a passagem no trato gastrintestinal de aves intactas, cecectomizadas e fistuladas no íleo terminal.

Westbrook, L. A. \& Cherian, G. Egg quality, fatty-acid composition and gastrointestinal morphology of layer hens fed whole flaxseed with enzyme supplementation. British Poultry Science, 60 (2), 146-153.

Williams, R. B. Intercurrent coccidiosis and necrotic enteritis of chickens: rational, integrated disease management by maintenance of gut integrity. Avian Pathology, 34 (3), 159-180.

Wilson, J., Tice, G., Brash, M. L. \& Hilaire, S. S. Manifestations of Clostridium perfringens and related bacterial enteritides in broiler chickens. World's Poultry Science Journal, 61 (3), 435-449.

Woyengo, T. A. \& Nyachoti, C. M. Supplementation of phytase and carbohydrases to diets for poultry. Canadian Journal of Animal Science, 91 (2), 177-192.

Xu, Z. R., Hu, C. H., Xia, M. S., Zhan, X. A. \& Wang, M. Q. Effects of dietary fructooligosaccharide on digestive enzyme activities, intestinal microflora and morphology of male broilers. Poultry Science, 82 (6), 1030-1036.

Yan, F., Dibner, J. J., Knight, C. D. \& Vazquez-Anon, M. Effect of carbohydrase and protease on growth performance and gut health of young broilers fed diets containing rye, wheat, and feather meal. Poultry Science, 96 (4), 817-828.

Yason, C. V., Summers, B. A. \& Schat, K. A. Pathogenesis of rotavirus infection in various age groups of chickens and turkeys. Pathology. American Journal of Veterinary Research, 48 (6), 927-938.

Zlotowski, P., Driemeier D. \& Barcellos, D. E. S. Patogenia das diarréias dos suínos: modelos e exemplos. Acta Scientiae Veterinariae. 36 (1), 81-86. 